\title{
Generic NPs and Habitual VPs
}

\author{
Allan Ramsay \\ Department of Computer Science \\ University College Dublin \\ Belfield, DUBLIN 4, Ireland
}

\begin{abstract}
We propose a simple, intuitively satisfying treatment of the semantics of bare plural NPs. This treatment avoids the use of nonstandard logics, and avoids the need for systematic ambiguity of verb semantics.
\end{abstract}

\section{Background}

Previous work on the semantics of bare plural NPs has largely focussed on the contribution they make in habitual sentences like

(1) Mary eats peaches.

and

(2) John likes driving fast cars.

Both (1) and (2) scem to express tendencies, general rules. If you heard (1) then you would feel confident that you could offer Mary a peach for dessert. (1) seems to express a general characteristic of Mary, namely that if you offer her a peach in a suitable situation she will eat it. If you heard (2) then you would hide the keys of your Ferrari when John was visiting. (2) tells you that if he gets the chance of driving a fast car he is likely to take it.

If we take (1) and (2) as paradigms of the way bare plural NPs get used then it is reasonable to suppose that they express some kind of general property. The NP peaches in (1), for instance, seems to express some relationship between Mary and peaches in general, or possibly between Mary and the property of being a peach. This feeling that bare plural NPs express general relationships has led to some rather desperate strategies. One is to suppose that they should be treated just as though they were universally quantified. The most cursory examination, however, shows that this cannot be right. It simply is not true that (1) entails that Mary has any relationship to the set of all peaches. It is not even true that it entails that she will always eat a peach if you offer her one in the right circumstances. Whatever bare plural NPs do, they do not act like universally quantified NPs.

A more sophisticated approach treats them as denoting properties. Chierchia and Turner [1987], for instance, interpret (1) as saying that Mary is in some relationship to the property of being a peach. There are two problems with this approach. The first is that they fail to be very explicit about what this relationship is, so that the proposal simply does not get us very far. The second is that whatever the relationship turns out to be we seem to end up with a systematic ambiguity in the meanings of simple verbs like eat. In

(3) Mary is eating a peach.

it looks as though the verb eat denotes a relation between two individuals, namely Mary and some peach. In (1), however, it must denote a relationship between an individual (Mary) and a property (the property of being a peach). Eat, it seems, is polymorphic. And so must every other verb which can take either an indefinite NP or a bare plural as complement be. Furthermore, there must be some systematic relation between the two interpretations of each of these verbs. It would surely be better to express this systematic relation in the semantics of the bare plural $N P s_{\text {, and }}$ to leave verbs like eat as relations between individuals.

Much the same can be said of Carlson's [1989] proposal that bare plurals denote extended individuals and indefinite NPs denote stages of individuals. If we take this approsch then (a) most English verbs must be polymorphic, accepting either extended individuals or stages of individuals as arguments, and (b) there must be some systematic relationship between these pairs of meanings. It is particularly disappointing that Carlson's discussion of this systematic relationship consists of the use of a type-raising operator $G n$ which is given no semantics.

A third approach is to try to capture the feeling that bare plurals indicate some sort of "tendency" by appealing to non-monotonic logic. Just as with the analysis in terms of universals, however, this just seems to get the intuitions wrong. What sort of nonmonotonic paraphrase can we give to (1)? It certainly 


$$
\begin{array}{r}
\text { presuppositions }=\{\iota(E, \forall H \text { member }(H, E) \\
+\operatorname{name}(H, j o h n) \\
\wedge|E|=1)\}]
\end{array}
$$

This says that there is a singleton set $A$ of "eating events"; that for each member of $A$ the agent is $E$ (remember, $A$ is a singleton set so there is in fact only one such member); that there is a singleton set $B$ of peaches which is the object of every member of $A$; that every member of $A$ is extended and took place at some past instant; and that the existence of a unique singleton set $E$ of itema called John is presupposed. It is easy to argue with the details of this analysis of (7), particularly with the temporal element, but the basic outline is familiar.

We now want an analysis of

(8) Mary was eating peaches.

which fits our intuition that (8) refers to an eating event whose agent was Mary and all of whose objects were peaches. The following seems suitable:

$$
\begin{aligned}
& {[\text { matrix }=\exists A \text { instant }(A) \wedge A<\text { now }} \\
& \wedge \exists B \forall C \text { member }(C, B) \\
& \rightarrow \operatorname{eat}(C) \\
& \wedge \operatorname{agent}(C, D) \\
& \wedge \forall E \text { object }(C, E) \\
& \rightarrow \operatorname{peach}(E) \\
& \wedge|B|=1 \\
& \wedge \forall F \text { member }(F, B) \\
& \rightarrow \text { instantaneous }(F) \\
& \wedge \operatorname{at}(A, F) \text {, } \\
& \text { presuppositions }=\{\iota(D, \forall G \text { member }(G, D) \\
& \rightarrow \operatorname{name}(G, \operatorname{mar} y) \\
& \wedge|D|=1)\}]
\end{aligned}
$$

This says that $B$ is a singleton set of instantaneous events; that the sole nember of this set took place at some past instant $A$; that its agent is the entity described by the presupposition that there is a single entity called Mary in the context; and that all its objects are peaches. This formal paraphrase seems to fit our intuitions about (8) perfectly. How did we obtain it?

\section{NP semantics}

We follow the tradition first established by Russell, and made concrete by Montague, of treating NP semantics as generalised quantifiers, i.e. as expressions which provide the quantificational information required for turning sorne proposition schema into a proposition. Montague, for instance, regards the meaning of every student as something like $\lambda(P, \forall X$ otudent $(X) \rightarrow P . X)$ (we use the notation
$P . X$ to denote the application of $P$ to $X$ ). Applying this to a property auch as $\lambda(Y, \operatorname{sleep}(Y))$ will produce the sentence $\forall X$ student $(X) \rightarrow \operatorname{sleep}(X)$. In general, the meaning of an $N P$ is treated in this tradition as something which will lower the type of an expression - something which will turn a property into a proposition, or a function from properties to properties into a property, or ...

We make one slight change to this analysis of NP semantics. The standard treatrnent of NPs says that they are of type $(e \rightarrow t) \rightarrow t$. In other words, they take a function which maps individualy (entities of type e) to truth values (entities of type t) and return a truth value. We propose to generalise a step further, making NP semantics map functions of type $(e \rightarrow t) \rightarrow t$ to truth values (i.e. that they are of type $((e \rightarrow t) \rightarrow t) \rightarrow t))$. Thus we propose that the matrix for every student should be $\lambda(A, A . \lambda(B, \forall C[\forall D$ member $(D, C) \rightarrow$ student $(D)] \rightarrow B . C))$. The embedded expression $\lambda(B, \forall C[\forall D$ member $(D, C) \rightarrow$ student $(D)] \rightarrow B . C)$ is similar to the generalised quantifier that standard model theoretic semantics provides for every student. The only difference is that we are quantifying over sets of students (i.e. over sets $C$ satsifying the requirement that $\forall D$ member $(D, C) \rightarrow$ student $(D))$ rather than over individuals. The meaning of the NP is then an expression which is waiting for something which will combine with this standard generalised quantifier. We will refer to such objects as generalised ${ }^{2}$ quantifiers, to emphasise the extra level of abstraction.

We obtain such representations of NP semantics in the usual way, by taking the meanings of determiners to be even higher level objects which get combined with the meanings of nominal groups. Thus the meaning of every is $\lambda(E, \lambda(A, A . \lambda(B, \vee G[\vee D$ member $(D, C) \rightarrow E . D] \rightarrow B . C)))$. Applying this to $\lambda(X$, student $(X))$, the menning of the nominal group consisting of the word student, produces $\lambda\left(A_{1} A . \lambda(B\right.$, $\forall C[\forall D$ member $(D, C) \rightarrow$ student $(D)] \rightarrow$ B.C)) as required. Similarly if the menning of $a$ is taken to be $\lambda(E, \lambda(A, \exists B[C$ member $(C, B) \rightarrow E . C] \wedge$ $|B|=1 \wedge A \cdot \lambda(D, D . B))$ ) then the meaning of a peach becomes $\lambda(A, \exists B[C$ member $(C, B) \rightarrow$ peach $(C)]$ $\wedge|B|=1 \wedge A \cdot \lambda(D, D . B))$. This is an abstraction over the proposition that there is some singleton set $B$ all of whose members are peaches which satisfies some complex property involving the abstracted variable, which is again what we require. Note that the application of $A$ in this formula is inside the scope of the quantification over members of $B$. It is this extra control over the relative scope of quantifiers that makes us prefer generalised ${ }^{2}$ quantifiers to ordinary generalised quantifiers. 
does not mean that Mary eats most peaches, in the sense that there is some relationship between Mary and more than half the peaches there either are now or ever have been. It does not mean that it is frequently, or even usually, the case that she can be found eating a peach (it is true, for instance, that I eat quails eggs, but it is certainly not true that it happens very often). The gut feeling that sentences like (1) and (2) express general tendencies, and that the best machinery we have for dealing with tendencies is non-monotonic logic, is very understandable. It does not, however, seem easy to give convincing formal paraphrases of sentences like these in these terms.

The problems with these suggestions arise from the fact (1) and (2) secm to express general tendencies, and that this is taken to be due the presence of the bare plurals NPs. Suppose we consider instead the occurrence of bare plural NPs in non-habitual sentences:

(4) Mary is eating peaches.

(5) John is driving fast cars.

(4) does not express any sort of tendency, any general rule. It describes a specific current event. There is an individual, Mary, who is doing something. What is she doing? She's eating. What is she eating? She is eating several things, each of which is a peach.

(5) does not even seem to make much sense. Why not? Because it seems to describe a specific driving event with a single agent but with several objects, each of which is a fast car. (5) scems odd because it seems to say that John is driving several fast cars at the same time, and we know that most people can only drive one car at a time.

We therefore suggest that the feeling that (1) and (2) express tendencies arises entirely from the form of the verb, and that bare plurals should be thought of as delimiting the arguments of the verb. In other words, we sugest that (4) should be thought of in much the same way as

(6) Mary is house-hunting.

which says what Mary is doing is hunting for something, and that what she is looking for is a house.

\section{Semantic Framework}

The treatment of bare plurals proposed in this paper Ats within the following general framework.

- Verbs denote events (subdivided into states, extended actions and instantaneous actions).
- There is a finite set of thematic roles, such as agent, instrument, target and object. The syntactic sub-categorisation rules of individual verbs allocate sets of items to these roles. These sets often turn out to be singletons, but it seems better to distinguish between singular and plural NPs in terms of the cardinality of some wet of objects than to say that singular NPs denote individuals and plurals denote aets.

- Tense and aspect express relations between events or sets of events and temporal objects such as instants and intervals.

- Definite reference and anaphora are treated as Presupposition-Inducing mechanisms. Presuppositions are described in terms of formulae each of which is required to pick out exactly one item in the context of an utterance. The semantics of any natural language expression consists of a set of such presuppositions and a matrix, which corresponds to the usual notion of propositional content.

The elements of this framework are not universally accepted, but they do at least all have respectable ancestors. The most contentious is the view that definite reference and anaphora should be dealt with in terms of constraints on the situation of utterance. The basic notion here is similar to the use of ANCHORs in situation semantics [Barwise \& Perry 1983], and to the treatment of anaphora in DRT [Kamp 1984]. The details of our approach are given in [Ramsay 1990a]. Very little in the present discussion of bare plurals depends on this treatment of definite reference. Sceptics about this part of our framework are invited to suspend their disbelief while considering the treatment of bare plurals.

The following analysis of

(7) John ate a peach.

should illustrate the crucial aspects of our representation:

$$
\begin{aligned}
& {[\text { matrix }=\exists A \exists B \forall C \text { member }(C, B) \rightarrow \operatorname{peach}(C)} \\
& \wedge|B|=1 \\
& \wedge \vee D \text { member }(D, A) \\
& \rightarrow \operatorname{eat}(D) \\
& \wedge \operatorname{agent}(D, E) \\
& \wedge|A|=1 \\
& \wedge \operatorname{abject}(D, B) \\
& \wedge \forall F \text { member }(F, A) \\
& \rightarrow \text { extended }(F) \\
& \wedge \exists G \text { instant }(G) \\
& \wedge G<\text { now } \\
& \wedge \operatorname{at}(G, F) \text {, }
\end{aligned}
$$


In order to interpret bare plural NPs we need the following rule:

$$
\begin{aligned}
& \text { [syntax }=[\text { major }=[\text { cat }=n, \text { bar }=2] \text {, } \\
& \text { head }=[\text { agree }=[\text { third }=[\text { sing }=\text { no, } \\
& \text { Hural }=\text { yes }] \text {, } \\
& \ldots \text {, } \\
& \text { misc }=[\text { slash }=\text { null, wh }=\text { no, } \ldots]] \text {, } \\
& \text { semantics }=[\text { matrix }=\lambda(I, Y . \lambda(J, \forall K(J . K \rightarrow L . K))) \text {, } \\
& \text { preauppositions }=M]] \\
& \Rightarrow
\end{aligned}
$$

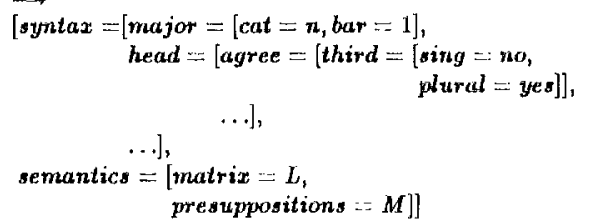

This rule, with quite bit of syntactic detail omitted, says that a plural nominal group (something of category $n$ and bar level 1) may be rewritten as an NP (something of category $\boldsymbol{n}$ and bar level 2). The matrix of the NP consists of a generalised ${ }^{2}$ quantifier derived from the matrix of the $\mathrm{NN}$, and the presuppositions of the NN are inherited by the NP.

This is exactly the rule we need to obtain

$$
\begin{aligned}
& {[\text { matrix }=\lambda(A, A . \lambda(B, V G B . C \rightarrow \text { peach }(C))),} \\
& \text { presuppositions }=\{\}]
\end{aligned}
$$

as the meaning of the bure plural peaches, and hence to obtain the interpretation given above of (8). It is worth noting that bare plurals as subject have very much the same effect - that the aralysis of

(9) Wolves were chasing a deer.

says that there was a past instantaneous chasing event whose object was a (singleton set of) deer and all of whose agenls were wolves:

$$
\begin{aligned}
& {[\text { matrix }=\exists A \text { instant }(A) \wedge A<\text { won } v} \\
& \wedge \exists B \forall C \text { member }(C, B) \\
& \rightarrow \operatorname{chase}\left(C^{\prime}\right) \\
& \wedge \vee D \operatorname{agent}(C, D) \\
& \rightarrow \text { woll } f(D) \\
& \wedge \exists E \forall F \text { member }(F, E) \\
& \rightarrow \operatorname{deer}(F) \\
& \wedge|\boldsymbol{E}|=1 \\
& \wedge \operatorname{abject}(C, E) \\
& \wedge|\boldsymbol{B}|=\mathbf{1} \\
& \wedge \vee G \text { member }(G, B) \\
& \rightarrow \text { instantaneous }(G) \\
& \wedge \operatorname{at}(A, G) \text {, }
\end{aligned}
$$

presuppositions $=\{\}]$

\section{Habituals Revisited}

The analysis given above seems to provide a satisfactory treatment of the contribution of bare plural NPs in sentences which report simple events. How do we deal with their use in habitual sentences like (1)?

We take it that (1) somehow expresses a general tendency. To say Mary eats peaches is to say that on suitable occasions she can be found eating peaches. The word "suitable" carries a lot weight here. If you aty Mary eats Beluga caviar, you probably mean that she eats it whenever she can get it. If you say Mary eats autsages you are unore likely to mean that she frequently eats them, probably because she's too poor to afford caviar very often. Indeed, the characterisation of "suitable" is likely to change from situation to situation even for the sante sentence. You could say She eats sausages in response to the question Is Mary a fussy eater?, in which case "suitable" might mean something like "if she's offered them and there's no other choice". You could also say it in response to the question Dots Mary have a heallhy varied diet? Here, "suitable" would be more likely to mean "on nearly every oceasion when she eats anything at all".

We suggest that the best way to deal with this is to treat habituals sa simply saying that events of the kind in question exist. The significance of snying that such events exist will depend on the situation in which it is said. Suppose you suy that events in which Mary eats suusages exist in a situation where your hearer wants to know about the existence of events where she eats things that some people might not like (i.e. in response to Is Mary a fussy eater?). In wuch a case the fuct that there are such events is enough to sutisfy the hearer's curiosity, and there are therefore no grounds for them to ussurne anything about how often she eats thern. Suppose, on the other hand, that you respond to a question about the variety of her diet by simply saying that there are occasions when she eats bausages. Your hearer is then likely to assume that you are implicatiug that these ure all or most of the "Mary exting something" events that you know ubout, since if you knew about other things Mary ate then you would know that her diet was reasonably varied. In other words, lubituals simply posit the existence of some set of events of the specified kind. Decisions about whether these events are common, about the circunistances in which they occur, can only be made on the basis of extra-linguistic contextual facts.

We therefore analyse the sentence

(10) Mary drives a fast car.

us:

$[$ maitix $=-\exists A \quad \exists B \vee C$ member $(C, B)$ 


$$
\begin{aligned}
& \rightarrow \operatorname{fast}(C, \lambda(D, \operatorname{car}(D))) \\
\wedge|B| & =1 \\
\wedge \forall E \operatorname{member}(E, A) & \rightarrow \operatorname{drive}(E) \\
& \wedge \operatorname{agent}(E, F) \\
& \wedge \operatorname{abject}(E, B) \\
\wedge|A|>1, & \\
\text { presuppositions }=\{\iota(F, \forall G \underset{\operatorname{member}(G, F)}{\rightarrow \operatorname{name}(G, \operatorname{mary})} & \wedge|F|=1)\}]
\end{aligned}
$$

This says that there is a set $A$ of driving events, where $A$ has more than one member; that each member of $A$ has Mary an its agent; and that there is some singleton set $B$ of fast cars (things which axe "fast for a car") which is the object of every member of $A$. How often she drives it, where she drives it, and so on are all questions which ean only be answered when we know more about the contert in which (10) was uttered. All that (10) actually says is that there is such a set of events.

This analysis of habituals gives a clue as to why

(11) Johr eats a peach.

does not seem to admit a habitual reading. The interpretation of (11) as

$$
\begin{aligned}
& {[\text { matrix }=\exists A \exists B \forall C \text { member }(C, B)} \\
& \rightarrow \text { peach }(C) \\
& \wedge|B|=1 \\
& \wedge \forall D \text { mamber }(D, A) \\
& \rightarrow \operatorname{eat}(D) \\
& \wedge \operatorname{agent}(D, E) \\
& \wedge \operatorname{object}(D, B) \\
& \wedge|A|>1 \\
& \text { presuppositions }=\{\iota(E, \forall F \text { member }(F, E) \\
& \rightarrow \operatorname{name}(F, j o h n) \\
& \wedge|E|=1)\}]
\end{aligned}
$$

says that there is a single peach which is the object of several eating events. Since a given peach can only be eaten once, this seems most unlikely.

There are, of course, still open questions concerning the interpretation of sentences like:

(12) John eats a peach for his lunch every day.

(12) clearly does require a habitual reading, where each day he eats a different peach. It seems likely that some mechanism such as "Cooper storage" [Cooper 1983, Keller 1987] for delaying decisions about quantifier scope will be required here. The exact details of this mechanism do not concern us here. We simply note that something of this kind seems to be necessary anyway for traditional problems of quantifier scope ambiguity. Since we will, for instance, need something like this for obtaining the de re/de dicto readings of
(13) John wants to catch a unicorn.

we will ausume that we will be able to rely on it for dealing with the relation between (11) and (12) as well. We end the current discussion by noting that our analyses of bare plurals and habituals do at least provide a sersible formal paraphrase of (1):

$$
\begin{aligned}
& {[\text { matrix }=\exists A \forall B} \text { member }(B, A) \\
& \rightarrow \operatorname{eat}(B) \\
& \wedge \text { agent }(B, C) \\
& \wedge \forall D \text { object }(B, D) \\
& \wedge \rightarrow \operatorname{peach}(D) \\
& \wedge|A|>1, \quad \\
& \text { presuppositions }=\{\iota(C, \forall E \text { member }(E, C) \\
& \rightarrow \operatorname{mame}(E, \operatorname{mar} y) \\
&\wedge|C|=1)\}]
\end{aligned}
$$

This analysis of (1) says that there are eating events whose agent is Mary and all of whose objects are peaches. This seems to be about as much as you can reasonably expect to get from (1) without some extra contextual informstion.

\section{Conclusions}

We have argued that the semantics of bare plurals can be captured without any extension to the formal underpinning of our semantic framework. The essential points were that (i) we separnted out the effects of the habitual aspect and of the bare plural; (ii) we assume that the fillers for thematic roles are always sets of items, with singular NPs denating singleton sets. This enables us to avoid postulating a syatematic polymorphism for verb semantics, with one interpretation in terms of individuals for cases where some argument is supplied by a singular NP and enother in terms of sets of individuals for cases where the same argument is supplied by a plural NP; and (iii) we used on event-oriented treatment of verb semantics (sce for instance Davidson [1980]). It is worth noting that Krifra [1990] and Pulman [1991] have also developed trestments of complex quantificational phenomens on the basis of this kind of treatment of verbs. The realisation that verbs can denote sets of events in the same way that NPs can denote sets of individuals, and that you can quantify over these as well over the individuals and sets of individuals denoted by $\mathrm{NP}_{\mathrm{s}}$, seems to provide a great deal of flexibility without increasing your ontological commitments.

The analyses of bare plurals and habituals discussed above have been implemented in a version of the system described in [Ramsay 1990a]. This aystem includes a left-corner chart parser, lerical entries containing subentegorisation frames, disjunctive unification of the kind described in [Ramsay 1990b], 
etc., etc., etc. All of the example semantic analyses were derived by this system. I would in fact say that unless you have a working implerientation of your grammar and sernantics, including antomatic $\beta$-reduction of applications of $\lambda$-abstractions, then the sheer complexity of the semantic formulae that arise will overwhelm you. Deciding, for instance, that using $\lambda(A, \exists B \forall C$ member $(C, B) \rightarrow D . C \wedge$ $|B|=1 \wedge A . \lambda(E, E . B))$ for the matrix of a led to more satisfactory analyses of indefinite NPs than $\lambda(A, A . \lambda(E, \exists B \forall C$ member $(C, B) \rightarrow D . C \wedge|B|=$ $1 \wedge(E . B)))$ would have been a great deal more tedious than it was if I had not had a system which would show me the consequences of the two choices in a variety of settings.

\section{REFERENCES}

Barwise J. \& Perry J. (1983): Situations and Attitudes: Bradford Books, Cambridge, MA.

Carlson G. (1989): On the Semantic Composition of English Generic Sentences, in Properties, Types and Meaning II: Semantic Issues (eds. G. Chierchia, B.H. Partee \& R. Turner): Kluwer Academic Publishers, Dordrecht: 167-192.

Chierchia G. \& Turner R. (1987): Semantics and Property Theory, Linguistics and Philosophy $11(3)$.

Cooper R. (1983): Quantificalion and Syntactic Theory: Reidel, Dordrecht.

Kamp H. (1984): A Theory of Truth and Semantic Representation, in Formal Methods in the Study of Language (eds. J. Groenendijk, J. Janssen \& M. Stokhof): Foris Publications, Dordrecht: $277-322$.

Keller W.R. (1987): Nested Cooper Storage: the Proper Treatment of Quantification in Ordinary Noun Phrases, CSRP. 73, University of Sussex.

Krifka M. (1990): Four Thousand Ships Passed through the lock: object-induced measure functions on events, Linguistics and Philosophy 13(5): $487-521$.

Puiman S.G. (1991): Comparatives and Ellipsis, Fifth Conference of the European Chapler of the Assoc. for Computational Linguistics, 2-7: .

Ramsay A.M. (1990a): The Logical Structure of English: Computing Senuntic Content: Pitman, London.

Ramsay A.M. (1990b): Disjunction Without Tears, Computational Linguistics 16(3): 171-174. 